\title{
Role of midwife-supported psychotherapy on antenatal depression, anxiety and maternal health: A meta-analysis and literature review
}

\author{
QING HAN, MIN GUO, FENFEN REN, DONGYUN DUAN and XIUFENG XU
}

Department of Obstetrics, Zaozhuang Hospital of Maternal and Child Health, Zaozhuang, Shandong 277100, P.R. China

Received December 23, 2019; Accepted February 14, 2020

DOI: $10.3892 / \mathrm{etm} .2020 .9011$

\begin{abstract}
The onset of depression and anxiety during the antenatal stage of pregnancy is common. Despite the conception of numerous interventions in the past decades, studies show no signs of decline in the prevalence of antenatal depression and anxiety. Recently, the use of midwife-supported psychotherapy to treat these psychosomatic disorders has garnered a lot of attention. However, no attempt to date has been made to synthesize the evidence evaluating the influence of midwife-supported psychotherapy on antenatal depression, anxiety, and overall maternal health-status. The aim of the present meta-analysis was to demonstrate the effectiveness of midwife-supported psychotherapy on depression, anxiety, and maternal health-status outcome during the antenatal stage of pregnancy. A systematic identification of literature was performed according to PRISMA guidelines on four academic databases: MEDLINE, Scopus, EMBASE and CENTRAL. A meta-analysis evaluated the influence of midwife-supported psychotherapy on depression, anxiety, and maternal health-status outcome as compared to conventional obstetric care. Of the 1,011 records, 17 articles, including 6,193 pregnant women (mean age: $28.9 \pm 2.2$ years) were included in this meta-analysis. Eleven studies compared the effects of midwife-supported therapy on depression, 14 compared its effects on anxiety and 2 compared its effects on maternal health-status outcome. The meta-analysis reveals the beneficial effects of midwife-supported psychotherapy for reducing depression (Hedge's g: -0.9), anxiety (-0.8) and enhancing maternal health-status outcome (0.1), as compared to conventional obstetric care. The current systematic review and meta-analysis recommend the use of midwife-supported psychotherapy for the reduction of depression, anxiety and enhancing maternal health-status during the antenatal stage of pregnancy.
\end{abstract}

Correspondence to: Mrs. Xiufeng Xu, Department of Obstetrics, Zaozhuang Hospital of Maternal and Child Health, 25 Wenhua East Road, Zaozhuang, Shandong 277100, P.R. China

E-mail: xuxiufengdc@outlook.com

Key words: perinatal, counselling, fear of birth, obstetrics, psychotherapy, gynecology

\section{Introduction}

The onset of depression and anxiety during the antenatal stage of pregnancy is prominent $(1,2)$. According to the World Health Organization, it is a substantial public and mental health concern for women of childbearing age $(3,4)$. Recent epidemiological studies suggest that approximately $15 \%$ of all pregnant women worldwide suffer from depression and anxiety-related disorders $(5,6)$. These levels have been reported to be even higher in low- and middle-income countries $(7,8)$.

Studies suggest a wide array of underlying pathophysiological mechanisms that may predispose the onset of these psychological disorders $(9,10)$. For instance, Leung and Kaplan (9) suggested pregnancy-induced changes in the maternal hormones, hypothalamus-pituitary axis (HP-axis), and levels of cortisol to be the main biological mechanisms behind the development of depression and anxiety. Meltzer-Brody (11) supported these outcomes and reported that changes in the level of hormones such as estrogen, estradiol, thyroxine, thyroid stimulation hormone, or prolactin, particularly during the third trimester, may lead to an HP-axis shift $(12,13)$. Furthermore, changes in epigenetic mechanisms, i.e., gene methylation due to varying antenatal conditions have been shown to act as a supplementary co-factor promoting depression and anxiety $(14,15)$. Similarly, a range of environmental (16), and socioeconomic factors (17), have been suggested to act as additional precursors for the development of these psychological disorders.

Depression and anxiety have been reported to impart a wide range of negative implications on maternal, fetal health outcomes (18). In terms of maternal health, high levels of antenatal anxiety (fear of childbirth) have been associated with higher incidences of surgical interventions (19), premature delivery (20), and pregnancy-related complications (18). In addition, a positive correlation was reported between the onset of antenatal depression with higher levels of postnatal depression and child-rearing stress (21). Existing studies have also reported a proportional relationship between these antenatal psychological disorders with fetal complications, such as inhibited fetal growth and hyperactivity $(22,23)$. Moreover, higher levels of anxiety and depression during pregnancy have also been reported to adversely impact maternal-fetal attachment and neonatal mental development (24). 
Despite previous medical advancements and the development of numerous novel interventions (25), epidemiological studies show no sign of decline in the onset of depression and anxiety during the antenatal stage of pregnancy (26). The main reason behind this could be negligence. In their review, Atif et al (27) mentioned that primary health care programs tend to focus more on maternal physical health as compared to mental health. The authors added that this prevalence was highest in developing countries where the treatment gap for managing antenatal depression and anxiety is as high as $85 \%$ (28). Conventionally, psychotherapeutic interventions are considered as front-line management approaches to alleviate depression and anxiety during the antenatal stage of pregnancy (29). However, scarcity of expert health care personnel and financial resources hinder the application of these interventions in middle- and low-income settings (30). Recent evidence promotes the use of non-specialist personnel for administering these interventions (30).

Taking this into consideration the use of midwife-supported psychotherapy has garnered a lot of attention $(31,32)$. Midwifery is an integral component of an obstetric care unit in low-, middle- and high-income countries (33). The approach has been reported to influence maternal and neonatal health-related outcomes during pregnancy (33-35). Previous findings suggest that the intricate midwife-mother-child bonding (36), cultural competence (37), community embeddedness (38), and cost-effectiveness (33), are potential underlying reasons making this approach successful $(31,39)$. Nevertheless, to date and to the best of our knowledge, no systematic review or meta-analysis has attempted to synthesize the evidence evaluating the effects of midwife-supported psychotherapy on depression and anxiety during the antenatal stage of pregnancy. Such an attempt would be useful for primary healthcare providers to determine best practice evidence for developing effective interventions for antenatal psychological care.

Therefore, in this present systematic review and meta-analysis, we aim to assess the role of midwife-supported psychotherapy on antenatal depression, anxiety, and maternal health-status outcome.

\section{Materials and methods}

This systematic review and meta-analysis was carried in adherence to PRISMA guidelines (40). A PRISMA checklist is provided in Table SI.

Data search strategy. We searched four academic databases (MEDLINE, CENTRAL, EMBASE and Scopus) from January 1960 until December 2019 using MeSH keywords: 'antenatal', 'pregnancy', 'perinatal', 'before-birth', 'pre-birth', 'psychotherapy', 'counselling', 'cognitive therapy', 'behavioral therapy', 'cognitive behavioral therapy', 'CBT', 'psychoeducation', 'interpersonal therapy', 'crisis oriented therapy', 'midwifery', 'midwife', 'nurse midwife', 'anxiety', 'depression', 'fear of birth', 'fear of child birth'. In addition, we screened the bibliography of the included studies for any additional relevant study.

Inclusion criteria for the studies were: i) Studies evaluating the efficacy of midwife-supported psychotherapy on depression, anxiety and health-status outcome during the antenatal stage of pregnancy. ii) Studies evaluating pregnant women in the antenatal stage of pregnancy. iii) Studies evaluating the depression, anxiety and/or maternal health-status outcome through a valid and reliable assessment method (e.g., State trait anxiety inventory, Edinburg perinatal depression scale, fear of birth scale, pregnancy worry and stress questionnaire, Wijma delivery expectancy scale, and EuroQol). iv) Studies were randomized controlled trials, quasi-randomized controlled trials, controlled clinical trials, prospective observational trials with control groups, or retrospective trials. v) Studies published in peer-reviewed scientific journals, conferences. vi) Studies published in English language.

The selection procedure was independently replicated via two reviewers to avoid biasing. Data extracted from the included studies were: authors, sample description (sex, age), method of assessment, intervention, comparator, stage of assessment and outcome measures. In the articles where quantitative data outcomes were incomplete or not mentioned the reviewers made attempts to contact respective corresponding authors for additional data.

Quality assessment. Risk of bias in the included studies was assessed by Cochrane's risk of bias assessment tool for randomized controlled trials and non-randomized controlled trials, i.e., ROBINS-I $(41,42)$. The included studies were independently appraised via two reviewers. The appraisal was performed based on the presence of low, high or unclear risk of bias. The thresholds for interpretation of Cochrane's risk of bias assessment tool according to the Agency for Healthcare Research and Quality standards was: good quality (all criteria are attained), fair quality (one high-risk criteria or two unclear criteria) or poor quality (two or more criteria attained with high risks). Inadequate randomization, concealment of allocation and reporting of selective outcomes were considered as major threats for biasing (43). In cases of ambiguity, discussions were held between the reviewers until a consensus was reached. Moreover, a level of evidence analysis based on the Center for Evidence-Based Medicine outcome was reported based on the type of included studies (44).

Data analysis. A within group meta-analysis of the included studies was carried out using CMA (Comprehensive Meta-analysis version 2.0) (45). The data were distributed and separately analyzed for depression, anxiety, and maternal health-status outcomes. A meta-analysis was conducted based on the random effects model (46). The effect sizes are reported as weighted Hedge's g. The threshold for interpreting the weighted effect sizes were: $\leq 0.2$, small effect; $\leq 0.5$, medium effect; and $\geq 0.8$, large effect (47). Heterogeneity was assessed using computing $\mathrm{I}^{2}$ statistics. The threshold for interpreting heterogeneity was: $0-25 \%$ with negligible heterogeneity; $25-75 \%$ with moderate heterogeneity; and $\geq 75 \%$ with substantial heterogeneity (48). Sensitivity analyses were performed in cases where substantial sources of heterogeneity persisted (49). In the present meta-analysis, based on the presence or absence of inadequate randomization methods in the studies, the results were included or excluded. For each evaluated parameter details of weighted effect size, $95 \%$ confidence intervals (CIs), level of significance and heterogeneity were duly reported. In addition, publication bias was analyzed by performing the trim 


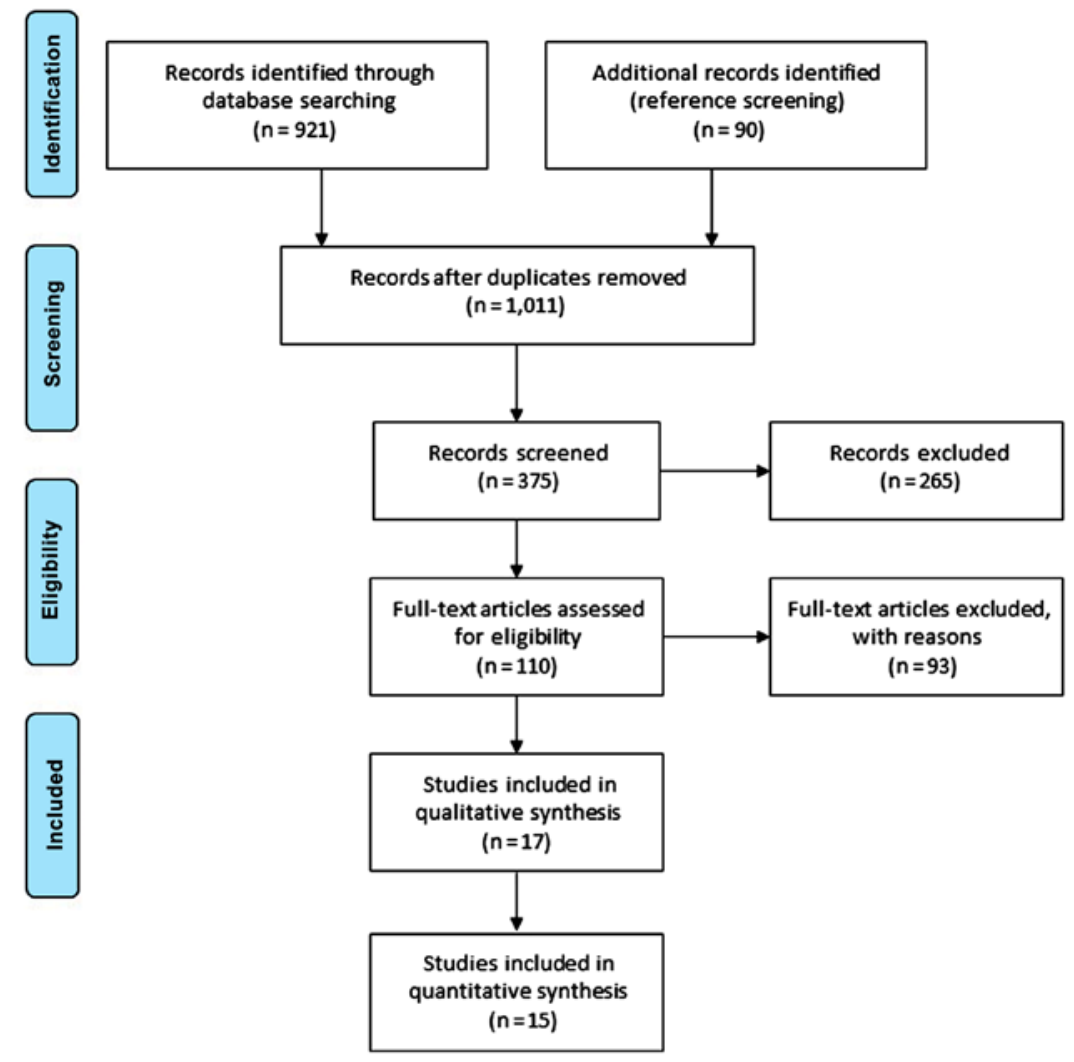

Figure 1. PRISMA flow chart for the included studies.

and fill procedure (50). This non-parametric method estimates the number of missing studies and computes the effect that these studies may have on the outcome of meta-analyses. Asymmetric studies were imputed from the left side of the plotted graph to identify the unbiased effect. Thereafter, these trimmed effects were refilled in the plotted graph and then the combined effect recalculated. In the present review, the alpha level was set at $5 \%$.

\section{Results}

A preliminary search on four academic databases resulted in a total of 921 studies, 90 more studies were included after the bibliography of these articles were screened (Fig. 1). Thereafter, following exclusion of the duplicates and applying the inclusion criteria, a total of 17 studies were retained.In the included studies, 12 were randomized controlled trials $(32,51-61)$, whereas five were controlled clinical trials (35,62-65). Significant reduction $(\mathrm{P}<0.05)$ in depression and anxiety was reported in 13 of the included studies which received midwife-supported psychotherapy $(19,32,51,52,54-58,60-62,64)$. Two studies reported an insignificant reduction $(\mathrm{P}>0.05)(53,59)$, and two studies reported no effect $(63,65)$, of midwife-supported psychotherapy on depression, anxiety and maternal health-status outcome during the antenatal stage of pregnancy. Qualitative and quantitative data were then extracted from all the studies and summarized in Table I.

\section{Risk of bias}

Randomized controlled trials. The risk of bias for the randomized controlled trials according to Cochrane's risk of bias assessment tool for randomized controlled trials is presented in Table II. The overall risk in the included studies was poor. The highest risk of bias was observed to be due to lack of blinding of the participants, researchers, outcomes, and due to lack of concealed allocation (Fig. 2). A level of evidence of $1 \mathrm{~b}$ was observed for all the included studies based on their experimental design.

Controlled clinical trials. The prevalence of risk of bias for the controlled clinical trials according to Cochrane's risk of bias assessment tool for non-randomized controlled trials ROBINS-I is presented in Table III. The overall risk in the included studies was again poor. The highest risk of bias was observed to be due to the lack of clarity in the confounding factors, and outcome measurement (Fig. 3). Furthermore, the studies refrained from explaining the measures they undertook to manage missing data and/or analyses for intention to treat analysis. A level of evidence of $2 b$ was observed for all the included studies based on their experimental design.

Publication bias. The trim and fill procedure identified two missing studies on the left side of the mean effect (Fig. 4). In addition, according to the random effects model, the point estimates and $95 \%$ confidence intervals for the evaluated parameters were $-0.8(-1.1$ to -0.5$)$. The trim and fill procedure report the imputed point estimate as -0.9 (-1.1 to 0.5$)$.

Participant information. A total of 6,193 pregnant women were evaluated in the studies included in this review. From these, a total of 1,636 women were a part of the experimental group where midwife-supported psychotherapy was administered, whereas 4,557 women were a part of the control group receiving conventional obstetric care. Eight of the included studies did not mention the age of the included sample $(19,32,51,55,56,62,63,65)$. However, 


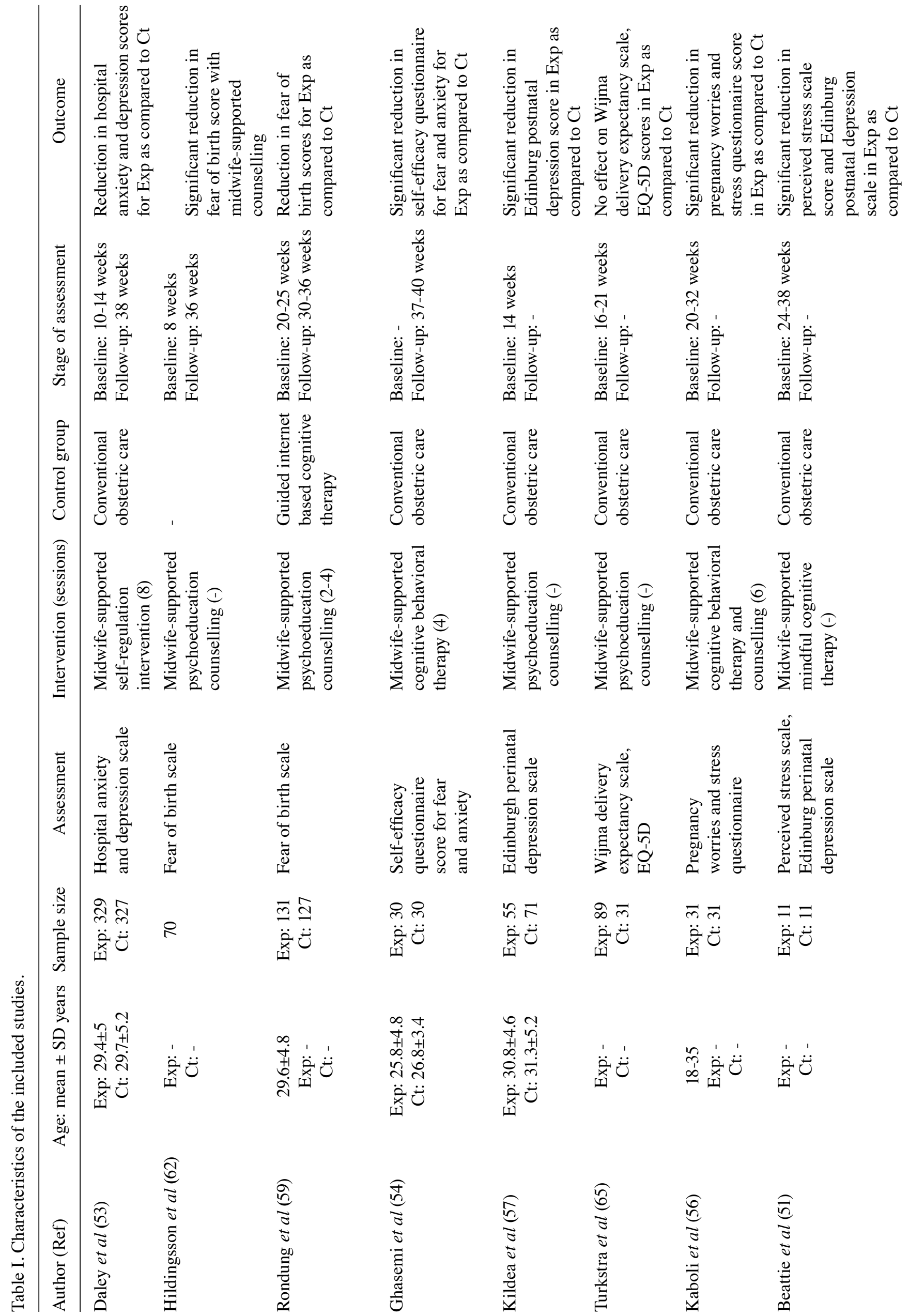




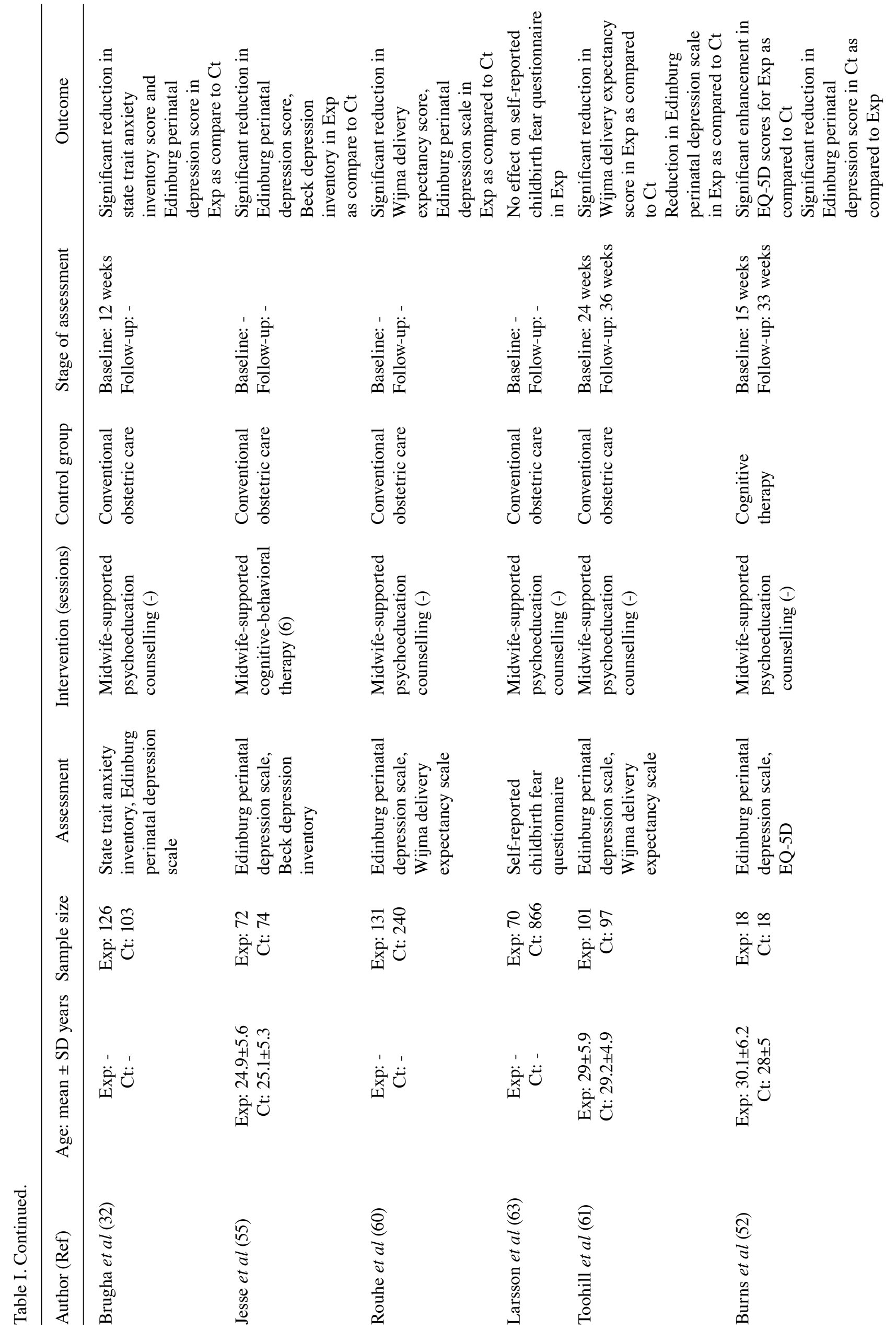




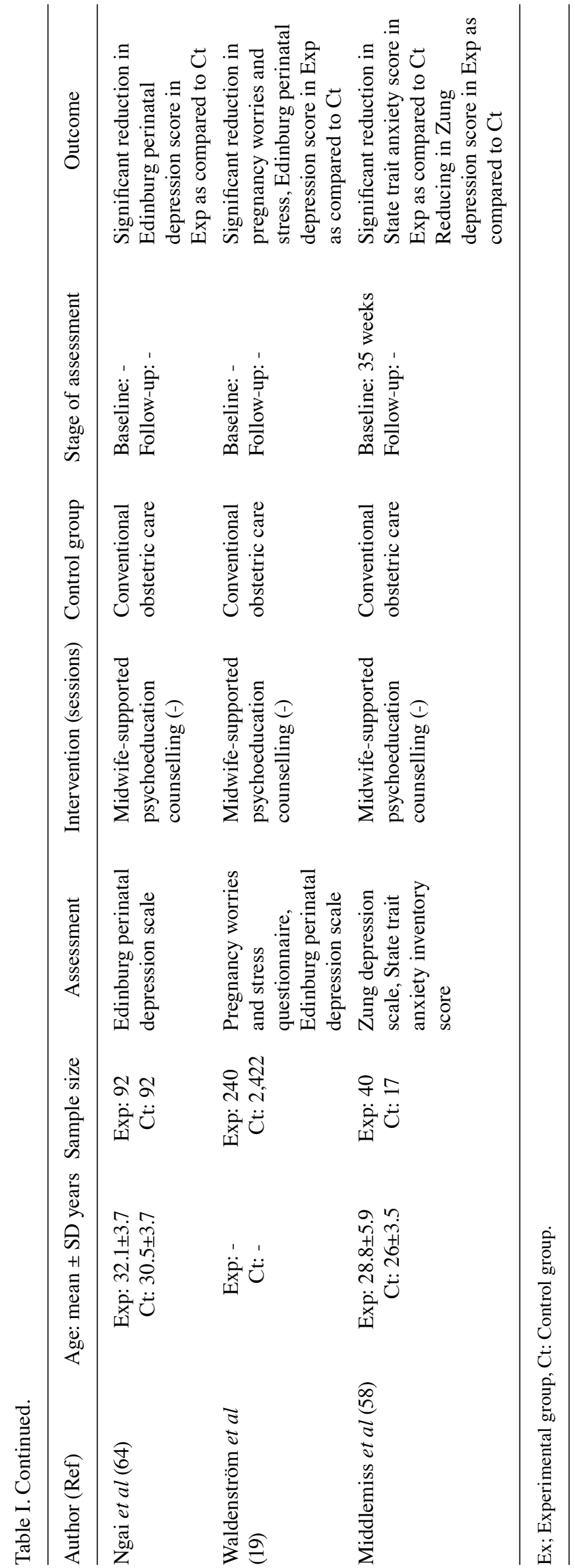



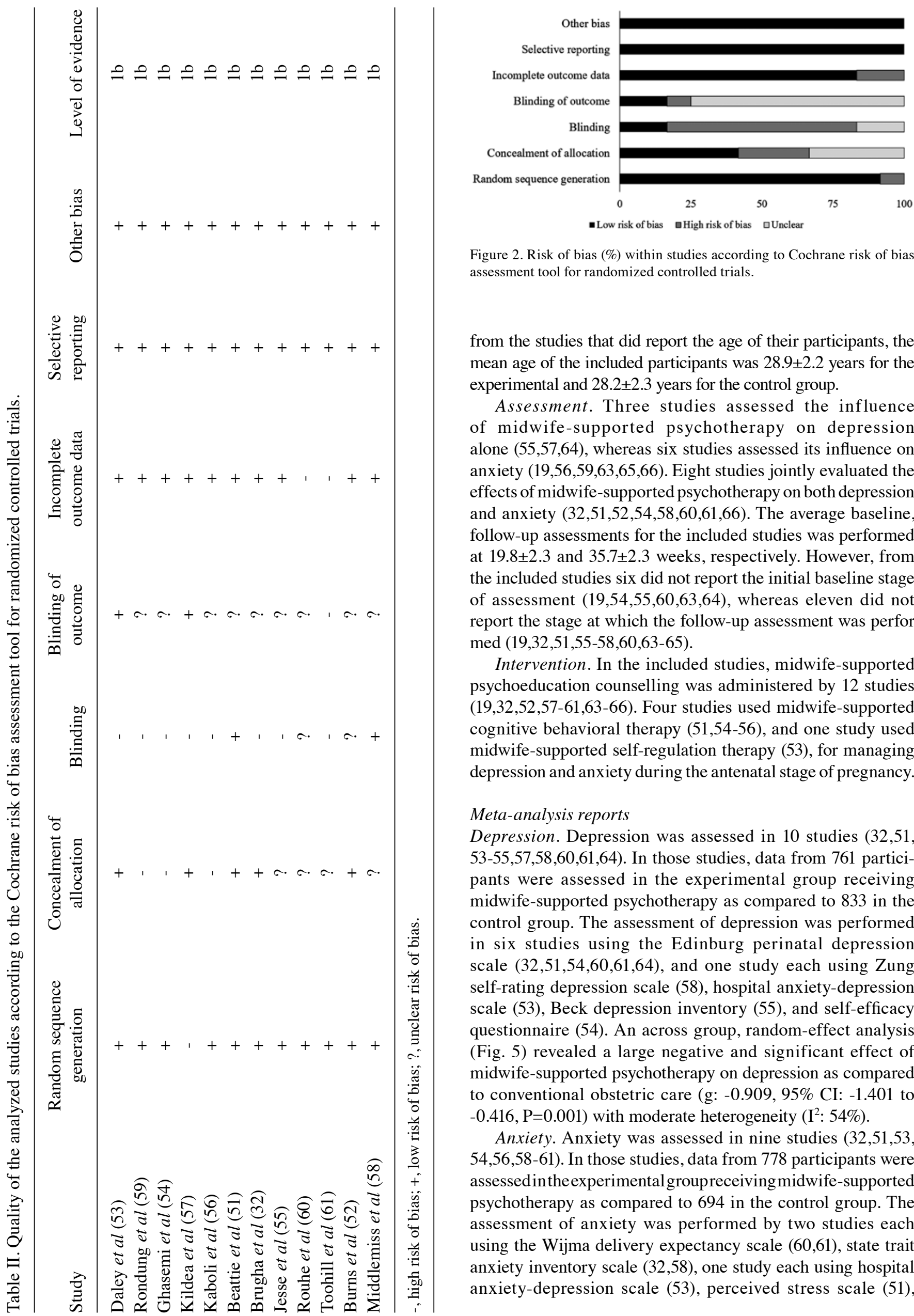

Figure 2. Risk of bias (\%) within studies according to Cochrane risk of bias assessment tool for randomized controlled trials.

from the studies that did report the age of their participants, the mean age of the included participants was $28.9 \pm 2.2$ years for the experimental and $28.2 \pm 2.3$ years for the control group.

Assessment. Three studies assessed the influence of midwife-supported psychotherapy on depression alone $(55,57,64)$, whereas six studies assessed its influence on anxiety $(19,56,59,63,65,66)$. Eight studies jointly evaluated the effects of midwife-supported psychotherapy on both depression and anxiety $(32,51,52,54,58,60,61,66)$. The average baseline, follow-up assessments for the included studies was performed at $19.8 \pm 2.3$ and $35.7 \pm 2.3$ weeks, respectively. However, from the included studies six did not report the initial baseline stage of assessment $(19,54,55,60,63,64)$, whereas eleven did not report the stage at which the follow-up assessment was perfor med (19,32,51,55-58,60,63-65).

Intervention. In the included studies, midwife-supported psychoeducation counselling was administered by 12 studies (19,32,52,57-61,63-66). Four studies used midwife-supported cognitive behavioral therapy $(51,54-56)$, and one study used midwife-supported self-regulation therapy (53), for managing depression and anxiety during the antenatal stage of pregnancy.

\section{Meta-analysis reports}

Depression. Depression was assessed in 10 studies $(32,51$, $53-55,57,58,60,61,64)$. In those studies, data from 761 participants were assessed in the experimental group receiving midwife-supported psychotherapy as compared to 833 in the control group. The assessment of depression was performed in six studies using the Edinburg perinatal depression scale $(32,51,54,60,61,64)$, and one study each using Zung self-rating depression scale (58), hospital anxiety-depression scale (53), Beck depression inventory (55), and self-efficacy questionnaire (54). An across group, random-effect analysis (Fig. 5) revealed a large negative and significant effect of midwife-supported psychotherapy on depression as compared to conventional obstetric care (g: $-0.909,95 \% \mathrm{CI}:-1.401$ to $-0.416, \mathrm{P}=0.001)$ with moderate heterogeneity $\left(\mathrm{I}^{2}: 54 \%\right)$.

Anxiety. Anxiety was assessed in nine studies $(32,51,53$, 54,56,58-61). In those studies, data from 778 participants were assessed in the experimental groupreceiving midwife-supported psychotherapy as compared to 694 in the control group. The assessment of anxiety was performed by two studies each using the Wijma delivery expectancy scale $(60,61)$, state trait anxiety inventory scale $(32,58)$, one study each using hospital anxiety-depression scale (53), perceived stress scale (51), 

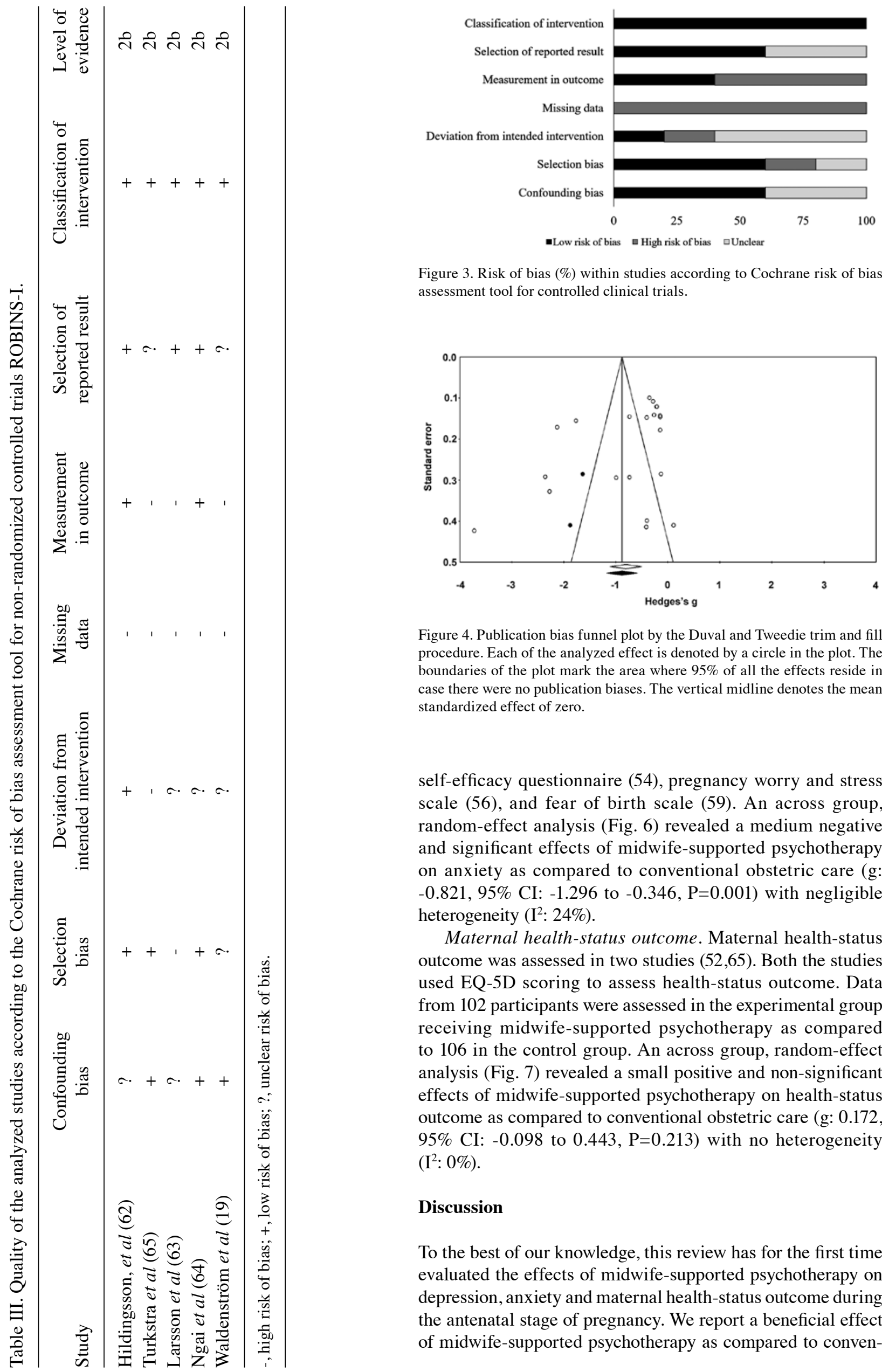

Figure 3. Risk of bias (\%) within studies according to Cochrane risk of bias assessment tool for controlled clinical trials.

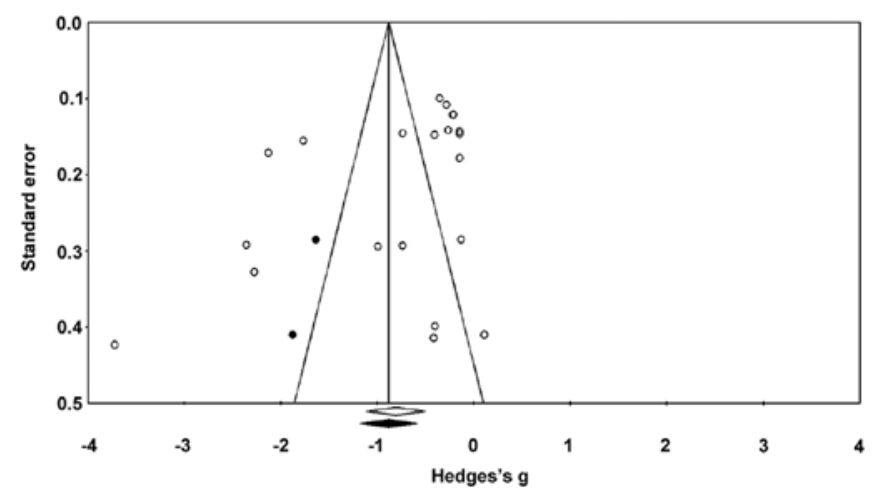

Figure 4. Publication bias funnel plot by the Duval and Tweedie trim and fill procedure. Each of the analyzed effect is denoted by a circle in the plot. The boundaries of the plot mark the area where $95 \%$ of all the effects reside in case there were no publication biases. The vertical midline denotes the mean standardized effect of zero.

self-efficacy questionnaire (54), pregnancy worry and stress scale (56), and fear of birth scale (59). An across group, random-effect analysis (Fig. 6) revealed a medium negative and significant effects of midwife-supported psychotherapy on anxiety as compared to conventional obstetric care (g: $-0.821,95 \%$ CI: -1.296 to $-0.346, \mathrm{P}=0.001)$ with negligible heterogeneity $\left(I^{2}: 24 \%\right)$.

Maternal health-status outcome. Maternal health-status outcome was assessed in two studies $(52,65)$. Both the studies used EQ-5D scoring to assess health-status outcome. Data from 102 participants were assessed in the experimental group receiving midwife-supported psychotherapy as compared to 106 in the control group. An across group, random-effect analysis (Fig. 7) revealed a small positive and non-significant effects of midwife-supported psychotherapy on health-status outcome as compared to conventional obstetric care (g: 0.172, $95 \%$ CI: -0.098 to $0.443, \mathrm{P}=0.213$ ) with no heterogeneity (I': $0 \%)$.

\section{Discussion}

To the best of our knowledge, this review has for the first time evaluated the effects of midwife-supported psychotherapy on depression, anxiety and maternal health-status outcome during the antenatal stage of pregnancy. We report a beneficial effect of midwife-supported psychotherapy as compared to conven- 
Study name

$\begin{array}{lcc} & \begin{array}{c}\text { Hedges's } \\ \text { g }\end{array} & \begin{array}{c}\text { Standard } \\ \text { error }\end{array} \\ \text { Daley et al., (2019) } & -0.207 & 0.122 \\ \text { Kidea et al., (2018) } & -0.142 & 0.179 \\ \text { Ghaseri et al., (2018) } & -3.714 & 0.424 \\ \text { Beattie et al., (2017) } & -0.410 & 0.415 \\ \text { Bugha et al. (2016) } & -1.763 & 0.156 \\ \text { Jesse et al., (2015) } & -2353 & 0.293 \\ \text { Tochil et al., (2014) } & -0.262 & 0.142 \\ \text { Rouhe et al., (2014) } & -0.279 & 0.109 \\ \text { Ngai et al., 2009 } & -0.402 & 0.148 \\ \text { Middlemiss et al., (1989) } & -0.126 & 0.286 \\ & -0.909 & 0.251 \\ \text { 12:54\% } & & \end{array}$

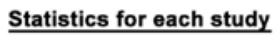

$\begin{array}{ccc}\text { Variance } & \begin{array}{l}\text { Lower } \\ \text { limit }\end{array} & \begin{array}{c}\text { Upper } \\ \text { limit }\end{array} \\ 0.015 & -0.446 & 0.032 \\ 0.002 & -0.492 & 0.208 \\ 0.180 & -4.546 & -2883 \\ 0.172 & -1.224 & 0.403 \\ 0.024 & -2069 & -1.457 \\ 0.066 & -2927 & -1.779 \\ 0.020 & -0.540 & 0.017 \\ 0.012 & -0.492 & -0.065 \\ 0.022 & -0.693 & -0.112 \\ 0.062 & -0.66 & 0.434 \\ 0.063 & -1.401 & -0.416\end{array}$

Hedges's $\mathrm{g}$ and $95 \% \mathrm{Cl}$

Z-Value
-1.695
-0.794
-8.757
-0.909
-11.306
-8.034
-1.840
-2550
-2713
-0.441
-3.616

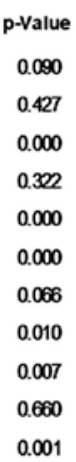

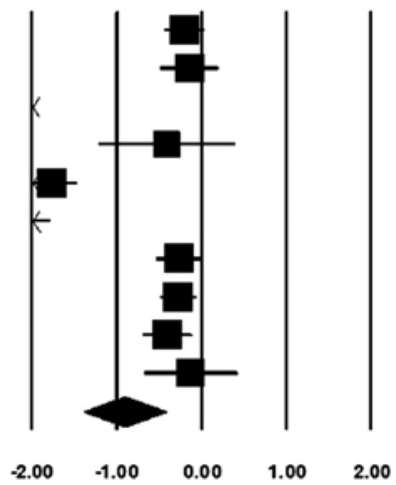

Figure 5. Forest plot for studies evaluating the effects of midwife-supported psychotherapy on the outcome of depression during the antenatal stage of pregnancy. Weighted effect size is presented as boxes, $95 \% \mathrm{CI}$ are presented as whiskers. A negative effect represents a reduced outcome of depression; a positive effect represents an enhanced outcome of depression.

$\underline{\text { Study name }}$

$\begin{array}{llc} & \begin{array}{c}\text { Hedges's } \\ \text { g }\end{array} & \begin{array}{c}\text { Standard } \\ \text { error }\end{array} \\ \text { Daley et al., (2019) } & -0.212 & 0.122 \\ \text { Ronding et al., (2018) } & -0.142 & 0.144 \\ \text { Ghaseni et al., (2018) } & -2.268 & 0.328 \\ \text { Kaboli et al., (2017) } & -0.989 & 0.295 \\ \text { Berttie et al., (2017) } & 0.114 & 0.411 \\ \text { Bugha et al. (2016) } & -2.123 & 0.172 \\ \text { Tochil et al., (2014) } & -0.732 & 0.146 \\ \text { Roune et al., (2014) } & -0.350 & 0.100 \\ \text { Mddlemiss et al., (1989) } & -0.734 & 0.294 \\ & -0.821 & 0.242\end{array}$

$\underline{\text { Statistics for each study }}$

$\begin{array}{rccr}\text { Variance } & \begin{array}{c}\text { Lower } \\ \text { limit }\end{array} & \begin{array}{c}\text { Upper } \\ \text { limit }\end{array} & \text { z-Value } \\ 0.015 & -0.451 & 0.027 & -1.738 \\ 0.021 & -0.424 & 0.140 & -0.985 \\ 0.108 & -2912 & -1.025 & -6.908 \\ 0.087 & -1.567 & -0.412 & -3.356 \\ 0.169 & -0.691 & 0.918 & 0.277 \\ 0.030 & -2460 & -1.786 & -12339 \\ 0.021 & -1.019 & -0.446 & -5.005 \\ 0.010 & -0.546 & -0.153 & -3.486 \\ 0.086 & -1.309 & -0.158 & -2.498 \\ 0.059 & -1.296 & -0.346 & -3.389\end{array}$

Hedges's g and $95 \% \mathrm{Cl}$

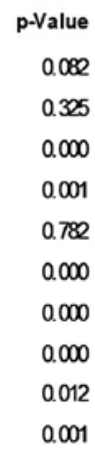

$12: 24 \%$

Figure 6. Forest plot for studies evaluating the effects of midwife-supported psychotherapy on the outcome of anxiety during the antenatal stage of pregnancy. Weighted effect size is presented as boxes, $95 \%$ CI are presented as whiskers. A negative effect represents a reduced outcome of anxiety; a positive effect represents an enhanced outcome of anxiety.

Study name

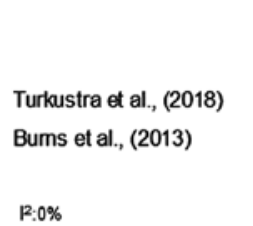

Statistics for each study

$\begin{array}{cc}\begin{array}{c}\text { Hedges's } \\ \mathbf{g}\end{array} & \begin{array}{c}\text { Standard } \\ \text { error }\end{array} \\ 0.142 & 0.147 \\ 0.397 & 0.400 \\ 0.172 & 0.138\end{array}$

Lower Upper

$\begin{array}{rcc}\text { Variance } & \begin{array}{c}\text { Lower } \\ \text { limit }\end{array} & \begin{array}{c}\text { Upper } \\ \text { limit }\end{array} \\ 0.022 & -0.147 & 0.430 \\ 0.160 & -0.386 & 1.181 \\ 0.019 & -0.098 & 0.443\end{array}$

$\begin{array}{rr}\text { Z-Value } & \text { p-Value } \\ 0.962 & 0.336 \\ 0.994 & 0.320 \\ 1.247 & 0.213\end{array}$

Hedges's $\mathrm{g}$ and $95 \% \mathrm{Cl}$

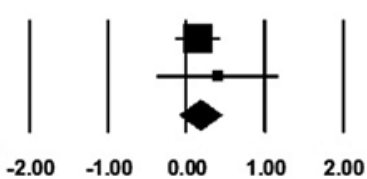

Figure 7. Forest plot for studies evaluating the effects of midwife-supported psychotherapy on maternal health-status outcome during antenatal stage of pregnancy. Weighted effect size is presented as boxes, 95\% CI are presented as whiskers. A negative effect represents a reduced EQ-5D score; a positive effect represents enhanced EQ-5D score.

tional obstetric care for alleviating depression and anxiety. Moreover, we report beneficial effects of midwife-supported psychotherapy for enhancing maternal health-status during the antenatal stage of pregnancy.

In the past decade, psychotherapeutic interventions have been extensively used as the first line of treatment to manage depression and anxiety during pregnancy $(67,68)$. Predominantly, the ability of this approach has been favored because of its capability to avoid pharmacological complica- tions (69). Wikner et al (70), for instance, reported the use of antidepressants such as Benzodiazepines during the antenatal stage of pregnancy to be highly associated with increased risks of poorer maternal health, fetal defects and congenital malformations (71). Furthermore, the use of psychotherapeutic interventions has been preferred because of their ability to enhance maternal motivation (72), allowing self-regulation of thoughts (73), and restructuring of negative emotions (74). In a systematic review, Sockol (75) reported that of all the 
psychotherapeutic interventions the efficacy of cognitive psychotherapy was far more superior in reducing and preventing the onset of depression during the later stages of pregnancy. The author mentioned that the complex cognitive procedures during cognitive psychotherapy could promote the development of a flexible and adaptive problem-solving approach for the patient which then, in turn, could be used to effectively reduce depression and anxiety $(75,76)$. Nevertheless, the use of these effective interventions has been marred by the shortfalls in terms of specialist personnel and finances especially in lowand middle-income countries $(77,78)$.

To counteract these detrimental effects, the use of non-specialist staff such as midwives for delivering psychotherapeutic interventions during the antenatal stage of pregnancy has been recommended in literature (79-81). Brugha et al (32), for instance, reported a substantial reduction in anxiety and depression with trained midwife-supported psychotherapy. The authors of that study reported that higher compliance, accessibility and confided emotional support offered by the midwives to be the main reasons behind these effects. Further work by Beattie et al (51) reported reduced depression and anxiety with midwife-supported behavioral therapy. Authors suggested that midwife-supported behavioral therapy could promote an enhanced state of acceptability during childbirth, which, in turn, could enhance the experience of labor $(51,82)$. In addition, a compassionate midwife-mother bonding could be an important reason which would have allowed enhancements in self-acceptability, awareness and social independence. In the current meta-analyses, we too observed large effect reduction in the levels of depression (Hedge's g: -0.909) and anxiety (g: -0.821) with midwife-supported psychotherapy.

In addition to reducing psychosomatic manifestations, midwife-supported therapy has also been reported to have beneficial effects on overall maternal health $(33,80)$. We presume that the ability of midwife-supported care to effectively impart antenatal care education could be a main reason behind its ability to enhance maternal health. Turkstra et al (65) reported that midwife-supported psychoeducation was, not only efficient in minimally enhancing the maternal health-outcomes (EQ-5D scores), but was also competent in reducing costs towards obstetric care. Accordingly, a recent Cochrane review also reported benefits of midwife-supported care on maternal health. The authors mentioned that mothers receiving midwife-supported care during the antenatal stage of pregnancy were less likely to experience severe labor-related pains and discomfort (83). Our findings concerning maternal-health outcomes are in line with the existing literature. In this present meta-analysis, we encountered small beneficial effect of midwife-supported psychotherapy for enhancing maternal health-status outcome (g: -0.998).

Finally, in the present literature review a few limitations persist. Firstly, this systematic review was not registered in a prospective registry such as PROSPERO. The reason for this lack of registration was that the communication delays from PROSPERO affected the preset project deadlines. Therefore, we decided to commence with the publication of this review even without the registration. We understand that this may raise questions concerning validity of this review. Secondly, a scarcity of statistical data in the included studies could have biased our interpretations concerning the influence of midwife-supported psychotherapy on maternal health-status outcome. The evaluation of health-status outcome was performed in only two studies including a total of 102, 106 women in the experimental and control groups, respectively. In this instance, the outcome due to a small sample size could possibly influence the results due to a type II error (84). We recommend future studies to address this paucity of data by evaluating health-status outcomes and sharing descriptive statistics in open access data repositories. Thirdly, as we incorporated broad inclusion criteria in our review study, we were able to include a wide range of studies assessing different midwife-supported psychotherapeutic interventions with different assessment tools. Due to this, moderate heterogeneity, i.e., $54 \%$ was observed in one of the meta-analysis reports analyzing the effects of midwife-supported psychotherapy on depression. Therefore, we would strongly recommend our readers to carefully interpret these results.

In conclusion, this systematic review and meta-analysis provides a $1 \mathrm{~b}$ level of evidence for the randomized controlled trials and a $2 b$ level of evidence for non-randomized controlled trials to support the use of midwife-supported psychotherapy to reduce depression, anxiety and enhance maternal health outcomes during the antenatal stage of pregnancy. The findings from the current meta-analyses can have widespread implications for developing best practice antenatal care approaches worldwide. However, further investigations are required to verify our findings.

\section{Acknowledgements}

Not applicable.

\section{Funding}

No funding was received.

\section{Availability of data and materials}

The datasets used and/or analyzed during the current study are available from the corresponding author on reasonable request.

\section{Authors' contributions}

$\mathrm{QH}$ and XX designed the paper. MG, FR, and DD were involved in literature search and data interpretation. QH, MG and FR were responsible for the data analysis. QH prepared the manuscript. XX edited the manuscript. All authors have read and approved the final manuscript.

\section{Ethics approval and consent to participate}

Not applicable.

\section{Patient consent for publication}

Not applicable.

\section{Competing interests}

The authors declare that they have no competing interests. 


\section{References}

1. Lee AM, Lam SK, Sze Mun Lau SM, Chong CS, Chui HW and Fong DY: Prevalence, course, and risk factors for antenatal anxiety and depression. Obstet Gynecol 110: 1102-1112, 2007.

2. Pawlby S, Hay DF, Sharp D, Waters CS and O'Keane V: Antenatal depression predicts depression in adolescent offspring: Prospective longitudinal community-based study. J Affect Disord 113: 236-243, 2009.

3. Fisher J, Cabral de Mello M, Patel V, Rahman A, Tran T, Holton S and Holmes W: Prevalence and determinants of common perinatal mental disorders in women in low- and lower-middle-income countries: A systematic review. Bull World Health Organ 90: 139G-149G, 2012.

4. Husain N, Bevc I, Husain M, Chaudhry IB, Atif N and Rahman A: Prevalence and social correlates of postnatal depression in a low income country. Arch Women Ment Health 9: 197-202, 2006.

5. Engle PL: Maternal mental health: Program and policy implications. Am J Clin Nutr 89: 963S-966S, 2009.

6. Saxena S, Funk M and Chisholm D: World Health Assembly adopts Comprehensive Mental Health Action Plan 2013-2020. Lancet 381: 1970-1971, 2013.

7. Karmaliani R, Asad N, Bann CM, Moss N, Mcclure EM, Pasha O, Wright LL and Goldenberg RL: Prevalence of anxiety, depression and associated factors among pregnant women of Hyderabad, Pakistan. Int J Soc Psychiatry 55: 414-424, 2009.

8. Rahman A, Bunn J, Lovel H and Creed F: Association between antenatal depression and low birthweight in a developing country. Acta Psychiatr Scand 115: 481-486, 2007.

9. Leung BMY and Kaplan BJ: Perinatal depression: Prevalence, risks, and the nutrition link--a review of the literature. J Am Diet Assoc 109: 1566-1575, 2009.

10. Waters CS, Hay DF, Simmonds JR and van Goozen SHM: Antenatal depression and children's developmental outcomes: Potential mechanisms and treatment options. Eur Child Adolesc Psychiatry 23: 957-971, 2014.

11. Meltzer-Brody S: New insights into perinatal depression: Pathogenesis and treatment during pregnancy and postpartum. Dialogues Clin Neurosci 13: 89-100, 2011.

12. Gelman PL, Flores-Ramos M, López-Martínez M, Fuentes CC and Grajeda JPR: Hypothalamic-pituitary-adrenal axis function during perinatal depression. Neurosci Bull 31: 338-350, 2015.

13. Kammerer M, Taylor A and Glover V: The HPA axis and perinatal depression: A hypothesis. Arch Women Ment Health 9: 187-196, 2006.

14. Perera F and Herbstman J: Prenatal environmental exposures, epigenetics, and disease. Reprod Toxicol 31: 363-373, 2011.

15. Tarantino LM, Sullivan PF and Meltzer-Brody S: Using animal models to disentangle the role of genetic, epigenetic, and environmental influences on behavioral outcomes associated with maternal anxiety and depression. Front Psychiatry 2: 44, 2011

16. Nestler EJ, Barrot M, DiLeone RJ, Eisch AJ, Gold SJ and Monteggia LM: Neurobiology of depression. Neuron 34: 13-25, 2002.

17. Bleker LS, de Rooij SR and Roseboom TJ: Malnutrition and depression in pregnancy and associations with child behaviour and cognitive function: A review of recent evidence on unique and joint effects. Can J Physiol Pharmacol 97: 158-173, 2019.

18. Chung TK, Lau TK, Yip AS, Chiu HF and Lee DT: Antepartum depressive symptomatology is associated with adverse obstetric and neonatal outcomes. Psychosom Med 63: 830-834, 2001.

19. Waldenström U, Hildingsson I and Ryding EL: Antenatal fear of childbirth and its association with subsequent caesarean section and experience of childbirth. BJOG 113: 638-646, 2006.

20. Glover V and O'Connor TG: Effects of antenatal stress and anxiety: Implications for development and psychiatry. Br J Psychiatry 180: 389-391, 2002.

21. Misri S, Kendrick K, Oberlander TF, Norris S, Tomfohr L, Zhang $\mathrm{H}$ and Grunau RE: Antenatal depression and anxiety affect postpartum parenting stress: A longitudinal, prospective study. Can J Psychiatry 55: 222-228, 2010.

22. Field T, Diego M and Hernandez-Reif M: Prenatal depression effects on the fetus and newborn: A review. Infant Behav Dev 29: 445-455, 2006.

23. Nguyen TM and Castro LC: Hypertensive Disorders and Depression in Pregnancy: Pregnancy Complications and Fetal Versus Neonatal Outcomes. J Womens Health (Larchmt) 28: $1451-1453,2019$.
24. Brouwers EPM, van Baar AL and Pop VJM: Maternal anxiety during pregnancy and subsequent infant development. Infant Behav Dev 24: 95-106, 2001

25. Dennis CL, Ross LE and Grigoriadis S: Psychosocial and psychological interventions for treating antenatal depression. Cochrane Database Syst Rev 2007: CD006309, 2007.

26. Milgrom J, Schembri C, Ericksen J, Ross J and Gemmill AW: Towards parenthood: An antenatal intervention to reduce depression, anxiety and parenting difficulties. J Affect Disord 130: 385-394, 2011.

27. Atif N, Lovell K and Rahman A: Maternal mental health: The missing ' $m$ ' in the global maternal and child health agenda. Semin Perinatol 39: 345-352, 2015.

28. Demyttenaere K, Bruffaerts R, Posada-Villa J, Gasquet I, Kovess V, Lepine JP, Angermeyer MC, Bernert S, de Girolamo G, Morosini P, et al; WHO World Mental Health Survey Consortium: Prevalence, severity, and unmet need for treatment of mental disorders in the World Health Organization World Mental Health Surveys. JAMA 291: 2581-2590, 2004.

29. Middleton H, Shaw I, Hull S and Feder G: NICE guidelines for the management of depression. BMJ 330: 267-268, 2005.

30. Rahman A, Malik A, Sikander S, Roberts C and Creed F: Cognitive behaviour therapy-based intervention by community health workers for mothers with depression and their infants in rural Pakistan: A cluster-randomised controlled trial. Lancet 372: 902-909, 2008

31. Anderson T: Feeling Safe Enough to Let Go: The Relationship Between a Woman and her Midwife During the Second Stage of Labour. In: The Midwife-Mother Relationship. Kirkham K (ed). 2nd edition. Macmillan, Basingstoke, pp116-143, 2010.

32. Brugha TS, Smith J, Austin J, Bankart J, Patterson M, Lovett C, Morgan Z, Morrell CJ and Slade P: Can community midwives prevent antenatal depression? An external pilot study to test the feasibility of a cluster randomized controlled universal prevention trial. Psychol Med 46: 345-356, 2016.

33. ten Hoope-Bender P, de Bernis L, Campbell J, Downe S, Fauveau V, Fogstad H, Homer CS, Kennedy HP, Matthews Z, McFadden A, et al: Improvement of maternal and newborn health through midwifery. Lancet 384: 1226-1235, 2014.

34. Sandall J, Devane D, Soltani H, Hatem M and Gates S: Improving quality and safety in maternity care: The contribution of midwife-led care. J Midwifery Womens Health 55: 255-261, 2010.

35. Waldenström U and Turnbull D: A systematic review comparing continuity of midwifery care with standard maternity services. Br J Obstet Gynaecol 105: 1160-1170, 1998.

36. Attarha M, Keshavarz Z, Bakhtiari M and Jamilian M: The Outcome of Midwife-Mother Relationship in Delivery Room: A Qualitative Content Analysis. Health 8: 720-726, 2016.

37. Rorie JA, Paine LL and Barger MK: Primary care for women. Cultural competence in primary care services. J Nurse Midwifery 41: 92-100, 1996.

38. Hunter B: The importance of reciprocity in relationships between community-based midwives and mothers. Midwifery 22: 308-322, 2006.

39. Deery R and Hunter B: Emotion Work and Relationships. In: The Midwife-Mother Relationship. Kirkham M (ed). Palgrave Mcmillan, London, 2010.

40. Moher D, Liberati A, Tetzlaff $\mathrm{J}$ and Altman DG; PRISMA Group: Preferred reporting items for systematic reviews and meta-analyses: The PRISMA statement. PLoS Med 6: e1000097, 2009.

41. Jørgensen L, Paludan-Müller AS, Laursen DRT, Savović J, Boutron I, Sterne JA, Higgins JP and Hróbjartsson A: Evaluation of the Cochrane tool for assessing risk of bias in randomized clinical trials: Overview of published comments and analysis of user practice in Cochrane and non-Cochrane reviews. Syst Rev 5: 80, 2016.

42. Sterne JA, Hernán MA, Reeves BC, Savović J, Berkman ND, Viswanathan M, Henry D, Altman DG, Ansari MT, Boutron I, et al: ROBINS-I: A tool for assessing risk of bias in non-randomised studies of interventions. BMJ 355: i4919, 2016.

43. Viswanathan M, Ansari MT, Berkman ND, et al: Assessing the Risk of Bias of Individual Studies in Systematic Reviews of Health Care Interventions. In: Methods Guide for Effectiveness and Comparative Effectiveness Reviews. Agency for Healthcare Research and Quality (US), Rockville, MD, 2008.

44. Burns PB, Rohrich RJ and Chung KC: The levels of evidence and their role in evidence-based medicine. Plast Reconstr Surg 128: 305-310, 2011. 
45. Bax L, Yu LM,Ikeda N and Moons KG: A systematic comparison of software dedicated to meta-analysis of causal studies. BMC Med Res Methodol 7: 40, 2007.

46. Higgins JPT, Thompson SG and Spiegelhalter DJ: A re-evaluation of random-effects meta-analysis. J R Stat Soc Ser A Stat Soc 172: 137-159, 2009.

47. Rosenthal R: Parametric measures of effect size. In: The handbook of research synthesis. Russell Sage Foundation, New York, NY, pp231-244, 1994.

48. Higgins JPT and Thompson SG: Quantifying heterogeneity in a meta-analysis. Stat Med 21: 1539-1558, 2002.

49. Petitti DB: Approaches to heterogeneity in meta-analysis. Stat Med 20: 3625-3633, 2001.

50. Duval S and Tweedie R: Trim and fill: A simple funnel-plot-based method of testing and adjusting for publication bias in meta-analysis. Biometrics 56: 455-463, 2000.

51. Beattie J, Hall H, Biro MA, East C and Lau R: Effects of mindfulness on maternal stress, depressive symptoms and awareness of present moment experience: A pilot randomised trial. Midwifery 50: 174-183, 2017.

52. Burns A, O'Mahen $\mathrm{H}$, Baxter $\mathrm{H}$, Bennert $\mathrm{K}$, Wiles $\mathrm{N}$, Ramchandani P, Turner K, Sharp D, Thorn J, Noble S, et al: A pilot randomised controlled trial of cognitive behavioural therapy for antenatal depression. BMC Psychiatry 13: 33, 2013.

53. Daley A, Jolly K, Jebb SA, Roalfe A, Mackilllop L, Lewis A, Clifford S, Usman M, Ohadike C, Kenyon S, et al: Effectiveness of a behavioural intervention involving regular weighing and feedback by community midwives within routine antenatal care to prevent excessive gestational weight gain: POPS2 randomised controlled trial. BMJ Open 9: e030174, 2019.

54. Ghasemi F, Bolbol-Haghighi N, Mottaghi Z, Hosseini SR and Khosravi A: The Effect of Group Counseling with Cognitive-Behavioral Approach on Self-Efficacy of Pregnant Women's Choice of Vaginal Delivery. Iran J Psychiatry Behav Sci In Press (In Press).

55. Jesse DE, Gaynes BN, Feldhousen EB, Newton ER, Bunch S and Hollon SD: Performance of a Culturally Tailored Cognitive-Behavioral Intervention Integrated in a Public Health Setting to Reduce Risk of Antepartum Depression: A Randomized Controlled Trial. J Midwifery Womens Health 60: 578-592, 2015.

56. Kaboli KS, Mahmoodi Z, Tourzani ZM, Tehranizadeh M, Kabir K and Dolatian M: The Effect of Group Counseling Based on Cognitive-Behavioral Approach on Pregnancy-Specific Stress and Anxiety. Shiraz E Med J (In Press)

57. Kildea S, Simcock G, Liu A, Elgbeili G, Laplante DP, Kahler A, Austin MP, Tracy S, Kruske S, Tracy M, et al: Continuity of midwifery carer moderates the effects of prenatal maternal stress on postnatal maternal wellbeing: The Queensland flood study. Arch Womens Ment Health 21: 203-214, 2018.

58. Middlemiss C, Dawson AJ, Gough N, Jones ME and Coles EC: A randomised study of a domiciliary antenatal care scheme: Maternal psychological effects. Midwifery 5: 69-74, 1989.

59. Rondung E, Ternström E, Hildingsson I, Haines HM, Sundin Ö, Ekdahl J, Karlström A, Larsson B, Segeblad B, Baylis R, et al: Comparing Internet-Based Cognitive Behavioral Therapy With Standard Care for Women With Fear of Birth: Randomized Controlled Trial. JMIR Ment Health 5: e10420, 2018.

60. Rouhe H, Salmela-Aro K, Toivanen R, Tokola M, Halmesmäki E, Ryding EL and Saisto T: Group psychoeducation with relaxation for severe fear of childbirth improves maternal adjustment and childbirth experience - a randomised controlled trial. J Psychosom Obstet Gynaecol 36: 1-9, 2015.

61. Toohill J, Fenwick J, Gamble J, Creedy DK, Buist A, Turkstra E and Ryding EL: A randomized controlled trial of a psycho-education intervention by midwives in reducing childbirth fear in pregnant women. Birth 41: 384-394, 2014.

62. Hildingsson I, Karlström A, Rubertsson C and Haines H: Women with fear of childbirth might benefit from having a known midwife during labour. Women Birth 32: 58-63, 2019.

63. Larsson B, Karlström A, Rubertsson C and Hildingsson I: The effects of counseling on fear of childbirth. Acta Obstet Gynecol Scand 94: 629-636, 2015.

64. Ngai FW, Chan SWC and Ip WY: The effects of a childbirth psychoeducation program on learned resourcefulness, maternal role competence and perinatal depression: A quasi-experiment. Int J Nurs Stud 46: 1298-1306, 2009.
65. Turkstra E, Mihala G, Scuffham PA, Creedy DK, Gamble J, Toohill $\mathrm{J}$ and Fenwick J: An economic evaluation alongside a randomised controlled trial on psycho-education counselling intervention offered by midwives to address women's fear of childbirth in Australia. Sex Reprod Healthe 11: 1-6, 2017.

66. Hildingsson I, Rubertsson C, Karlström A and Haines H: A known midwife can make a difference for women with fear of childbirth- birth outcome and women's experiences of intrapartum care. Sex Reprod Healthc 21: 33-38, 2019.

67. Glover V: Maternal depression, anxiety and stress during pregnancy and child outcome; what needs to be done. Best Pract Res Clin Obstet Gynaecol 28: 25-35, 2014.

68. Stoll K, Swift EM, Fairbrother N, Nethery E and Janssen P: A systematic review of nonpharmacological prenatal interventions for pregnancy-specific anxiety and fear of childbirth. Birth 45: 7-18, 2018.

69. Dubovicky M, Belovicova K, Csatlosova K and Bogi E: Risks of using SSRI / SNRI antidepressants during pregnancy and lactation. Interdiscip Toxicol 10: 30-34, 2017.

70. Wikner BN, Stiller CO, Bergman U, Asker C and Källén B: Use of benzodiazepines and benzodiazepine receptor agonists during pregnancy: Neonatal outcome and congenital malformations. Pharmacoepidemiol Drug Saf 16: 1203-1210, 2007.

71. Arch JJ, Dimidjian S and Chessick C: Are exposure-based cognitive behavioral therapies safe during pregnancy? Arch Women Ment Health 15: 445-457, 2012.

72. Cho HJ, Kwon JH and Lee JJ: Antenatal cognitive-behavioral therapy for prevention of postpartum depression: A pilot study. Yonsei Med J 49: 553-562, 2008.

73. Beck R and Fernandez E: Cognitive-Behavioral Self-Regulation of the Frequency, Duration, and Intensity of Anger. J Psychopathol Behav Assess 20: 217-229, 1998.

74. Mueser KT, Gottlieb JD, Xie H, Lu W, Yanos PT, Rosenberg SD, Silverstein SM, Duva SM, Minsky S, Wolfe RS, et al: Evaluation of cognitive restructuring for post-traumatic stress disorder in people with severe mental illness. Br J Psychiatry 206: 501-508, 2015.

75. Sockol LE: A systematic review of the efficacy of cognitive behavioral therapy for treating and preventing perinatal depression. J Affect Disord 177: 7-21, 2015.

76. Silverstein M, Feinberg E, Cabral H, Sauder S, Egbert L, Schainker E, Kamholz K, Hegel $M$ and Beardslee W: Problem-solving education to prevent depression among low-income mothers of preterm infants: A randomized controlled pilot trial. Arch Women Ment Health 14: 317-324, 2011.

77. Beck A, Nadkarni A, Calam R, Naeem F and Husain N: Increasing access to Cognitive Behaviour Therapy in Low and Middle Income Countries: A strategic framework. Asian J Psychiatr 22: 190-195, 2016.

78. Blane D, Williams C, Morrison J, Wilson A and Mercer S: Cognitive behavioural therapy: Why primary care should have it all. Br J Gen Pract 63: 103-104, 2013.

79. Chowdhary N, Sikander S, Atif N, Singh N, Ahmad I, Fuhr DC, Rahman A and Patel V: The content and delivery of psychological interventions for perinatal depression by non-specialist health workers in low and middle income countries: A systematic review. Best Pract Res Clin Obstet Gynaecol 28: 113-133, 2014.

80. Homer CSE, Friberg IK, Dias MAB, ten Hoope-Bender P, Sandall J, Speciale AM and Bartlett LA: The projected effect of scaling up midwifery. Lancet 384: 1146-1157, 2014.

81. Mendenhall E, De Silva MJ, Hanlon C, Petersen I, Shidhaye R, Jordans M, Luitel N, Ssebunnya J, Fekadu A, Patel V, et al: Acceptability and feasibility of using non-specialist health workers to deliver mental health care: Stakeholder perceptions from the PRIME district sites in Ethiopia, India, Nepal, South Africa, and Uganda. Soc Sci Med 118: 33-42, 2014.

82. Whitburn LY: Labour pain: From the physical brain to the conscious mind. J Psychosom Obstet Gynaecol 34: 139-143, 2013.

83. Sandall J, Soltani H, Gates S, Shennan A and Devane D: Midwife-led continuity models versus other models of care for childbearing women. Cochrane Database Syst Rev 4: CD004667, 2016.

84. Harmon LJ and Losos JB: The effect of intraspecific sample size on type I and type II error rates in comparative studies. Evolution 59: 2705-2710, 2005.

This work is licensed under a Creative Commons Attribution-NonCommercial-NoDerivatives 4.0 International (CC BY-NC-ND 4.0) License. 